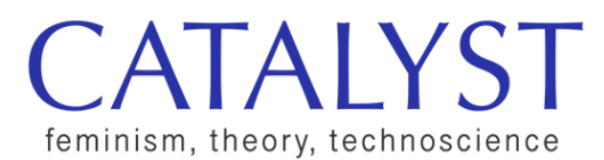

\title{
On Language, Scientific Metaphor, and Endocrine Disruption: An Interview with Feminist Scientist Ana Soto
}

\author{
Gracen Brilmyer \\ University of California Los Angeles \\ gracenbrilmyer@gmail.com
}

In the late 1980s, Professor of Immunology Ana Soto accidentally discovered the presence of synthetic estrogens in her lab equipment. Her lab had designed an experiment to test the effect of estrogen on the proliferation of human breast cancer cells $\left(\mathrm{MCF}_{7}\right)$. Based on previous findings, Soto and her research partner Carlos Sonnenschein believed that, contrary to popular wisdom, the introduction of estrogen would not directly induce the proliferation of the cells, but would instead interfere with a naturally occurring inhibitor in the blood. But the control setup containing positive and negative controls (used in the past without problem) was now producing odd readings: although no estrogenic compound had been introduced, the cancer cells were still proliferating. Soto and Sonnenschein methodically removed each item in the control setup that might be producing the estrogen-like result. When they discovered that the estrogenic activity leached from the plastic centrifuge tubes used to store components of the cell culture medium, they called the manufacturer to find out what could have changed. The manufacturer let them know that the constituent materials of the tubes had recently been modified in order to reduce the possibility of breakage during centrifugation but declined to reveal what specific changes had been made. So Soto's lab turned to studying the tubes themselves. After a year of further research, they concluded that the estrogenic activity was due to the 1-8. 
additive that had been introduced by the manufacturer-nonylphenol, an antioxidant used in numerous other applications, some of which are meant for human use (e.g., spermicide) and the synthesis of detergents. Soto and Sonnenschein's assay is called E-SCREEN and has been enormously influential; in fact, most of the environmental estrogens discovered in the 1990 s rely on the assay.

Conducted by Gracen Brilmyer at UCLA during the "Chemical Entanglements Symposium", this 2017 interview with Soto highlights her experiences of sexism in the sciences and how those experiences have shaped her thinking on language, science, and scholarship.

GB: I was really excited to talk to you especially because of the talk that you're giving at "Chemical Entanglements" about reflecting on your process and the question of "to whose benefit" science is conducted. Can you speak about how you arrived at the work that you are currently doing?

AS: I went to science out of curiosity: curiosity to understand things, to look at nature, to find out, "How is this all related? What does it mean?" When I was a kid, I was asking questions about those kinds of things without knowing much about any of them. My parents always took this seriously, in a way, so that sort of stimulated this interest. And probably that is where the feminism starts.

I didn't realize there was any difference in possibilities for career development for boys or girls. Even though my mother was a very cultured person, this was in the '50s, so she was taking care of the children. And then she went back to work, but not when we were children. So I couldn't see that I was going to be marked by the fact that I was a girl, because I was given all I wanted to read and understand the world.

But later on, when I went to university, there were a bunch of women, but you wouldn't believe how obvious [sexism] was. My anatomy professor said that we were there to catch husbands and things of that sort. And I got so upset that I said to him, "How could you know?" In my family I had been allowed to say anything reasonable, you see? They thought that it was nice that I liked science and arts, so I didn't realize that there was a world out there that wasn't really going to help. I started realizing that that was the way of the world. I still thought, "Okay, I'm accepted at the medical school, which is a place that not everyone goes." I didn't think that it was going to be that discriminatory because in the exam to enter medical school then, in Argentina, it was totally blind. There were no quotas for 
women or anything like that; the people who got the appropriate scores got in. I could see that women were mostly at home and men were mostly working, although some women obviously worked. I thought that maybe it was different for people my age. So, after the first year [in medical school in Argentina], I realized it was going to be very, very, very difficult. And that is when I realized, too, that I was going to leave my country because I thought that probably in the States or Europe the situation of women was better. I was very young, and I knew already that I wasn't going to die in the same place where I was born. And all that has to do with the fact that I am a woman.

Things started to be a little different once I was a postdoctoral fellow; there were women full professors and even a department chair at Tufts in the mid-'7os. A decade later, by accident, my scientific partner Carlos Sonnenschein and I discovered the first plastic estrogen. Thanks to contaminated lab results, we realized that [estrogen] was in the plastic [used to manufacture test tubes]. Jean Meyer, the president of Tufts University, was as puzzled as us by the results; he suggested that we send the tubes to the FDA. The FDA response to our estrogenin plastic problem was, "We'll get back to you soon." We are still waiting for their answer...We thought that it was going to be a two-year job or something like that for us to clean up the source [of the estrogen contamination] and go back to what we were doing before. But this was almost thirty years ago, and this public health problem has yet to be properly addressed.

Back to gender, somehow every day there is something that makes me to think of disparities and discrimination. Probably what I write professionally would not look much different if written by a male colleague. However, I would not use metaphors of domination or war; I am too aware of their nefarious effects.

You know, there is that famous story [told by anthropologist Emily Martin] about how men talk about fertilization and how women talk about fertilization. [Martin's book The Woman in the Body] was written in the '8os. From men's viewpoint, the sperm is trying to penetrate the egg. The female's story is about how the egg could really attract the sperm.

Sexism is everywhere and, being a woman, I am always sensitive to it. I try to make it clear to people to refrain from using language in such an unthoughtful way; a lot of it is unconscious bias-even women do it. But I also see hidden baggage in our concepts, and that is what took me to study philosophy of biology and to start doing theory of biology. For example, how the idea of a genetic program was adopted in biology. "Program" comes from logics, from mathematics. And there is something there that is immensely interesting because 
people didn't use the words "program," "information," or "signal" in biology until they took it from the mathematical theory of information. This mathematical theory does not deal with processes or things that exist in nature: logic is a human creation, and so are computers. But people use these mathematical ideas as if there were things present in the material world. This is exemplified by the story that the brain is a computer, a description that is absolutely metaphoric.

In brief, biologists took concepts from theories developed in mathematics and without any sort of examination incorporate them into biology, but not as strict and precise theories, but as metaphor. Then they say that the environment "reprograms" something that is not and could not be programmed. We think that the misuse of these metaphors is hindering progress in the biomedical sciences.

We are immersed in the world that we wish to understand. Hence, we can only have direct access to the objects that share the world with us through our situated perspective. To circumvent this, we can pretend to have a transcendent God's eye...but this is a dangerous scape. We perceive the world with our senses, and thus our way of perceiving it is per force different than that of an insect. In order for something to be science rather than science fiction or literature, we need to have a theory. Theories construct objectivity and determine the proper things or objects that can be studied by a given theory. And that is the beauty of science, that theories could be proven wrong and dismissed. Biology has only one general theory: this is the theory of evolution that deals with a very long-time scale, that of phylogeny. But we scientists interested in phenomena pertaining to the life cycle, from fertilization to death, in organisms, don't have such a theoretical frame. This is why I and a handful of colleagues are looking for principles to construct a theory of organisms. That, in a nutshell, is another dimension of this story of what we are doing, and it comes from knowing that the concepts we use to talk about things and processes are charged [with sociocultural meanings].

As the philosopher Dan Dennett stated, "There is no such thing as philosophy-free science; there is only science whose philosophical baggage is taken on board without examination." The hidden baggage is also contributing to the problems in regulating endocrine disruptors. For example, the problem is not just conflict of interest, and the fact that industry actively sells doubt, as established by historians of science Naomi Oreskes and Erik M. Conway. There is also the sociocultural imprinting of honest scientists.

[For instance, with endocrine disrupting chemicals (EDCs), ] the industry says, "Oh, you haven't identified a mechanism by which to link EDCs to a specific 
disease outcome," and many of these scientists immediately go to work again, when indeed we have enough evidence for regulating this class of chemicals. Because science is in a way bottomless. One can never have enough evidence. Science is not going to be complete anyway, so you keep going on. But that is science for its own sake. [We need to] become aware that when dealing with science for public health there is a point when enough is enough. Instead, many scientists would like to obtain more and more data to get to "the mechanism," and to arrive at "molecular explanations." Well, the idea that everything has to be explained via molecular mechanisms is not an immutable law of nature, but a philosophical stance called reductionism. Those philosophical stances, already abandoned by physicists more than a century ago, begat vague theories. If a theory is vague, it cannot be proven wrong. So that is, in a nutshell, the status of biology today. We urgently need to produce critical work, rejecting bad theories, elaborating new ones that are precise enough to be rejected...

I'm frustrated about the slow pace of regulatory action in the light of so much evidence that we've seen building up in the last twenty-five years. I'm frustrated because this is a very serious public health problem, not as much for people my age but for the people that are coming after us.

GB: You've talked about being a woman and how that made you more aware of the ways in which people use language to talk about scientific concepts. Do you think a feminist lens influences you in the way that you either understand the world or formulate questions about your own work?

AS: I think that I'm very much aware that nowadays women everywhere earn less than men. And even when they don't, like in the French university system, maybe they take longer to arrive at the same post.

I won't say that I'm obsessed by [feminism] because it's not that I'm in a perpetual state of alertness about gender discrimination. I see it when it's happening-when someone talks about a woman in a particular way without realizing that [what they are saying] is something that he or she wouldn't say of a man. And women do that, too. Of course, I'm a feminist and of course I was very much vocal about that when I was young; now I alert people when they use unconscious bias, so that they become aware of it and can choose to work on it.

GB: Do you think about the diversity of your students or of the people in your department? Given that the way your being a woman influences the way that you perceive the world and, from my perspective, really benefits your work a lot, do 
you try to prioritize diversity among students and the questions and different perspectives they bring in?

AS: I think that people bring with them a lot of different things and that is good, a real asset. I think that regardless of where you come from, when you enter a scientific discipline, you have to learn to ask questions about science and that is not as easy. I foster that in my students when I say, "If you are going to a conference, don't leave that conference without asking publicly your questions." Asking questions is not because you don't know something you should know, but because there is always some point that is not clear, some assumption that is hidden, etc. Indeed, there are many things that we do not know. Thus, it is normal and necessary that each of us have questions for anyone that is talking about her/his research. So you will sit there and ask questions mentally and then ask questions and observe how others ask questions. And by the end of the meetingand it depends on how long the meeting is-you have to at least do one, two, or three interventions. Once they try this a few times, it becomes second nature. This is the way it should be.

GB: Do you see science as a creative process?

AS: Oh, yes! My sister is an artist and we can talk about our creative lives. It's amazing because we can talk to each other about the constraints of our work and how you have to understand those constraints or else you'll get knocked down by them. People think in metaphors. Human language is metaphors. The difference for me is that you can use a metaphor as a painter, or a writer and it goes far, but when you're a scientist the metaphor is useful to "see" something, but then you have to make it clear to yourself that this is a metaphor and avoid "reifying" it. Once you make it thing-like, believing that there is a genetic program, you are doing something dangerous that sooner or later will lead you astray.

This is exactly what happened with the introduction of the terms program, information, and signal in biology. That is why when people talk about why there are so many problems regarding lack of reproducibility, it has to do with this: if you don't have a theory, you can push things this way or that way because you don't have the constraints of a good theory (a theory that is not vague, and thus, could be found to be wrong and if so, refuted). And when you start to find results that cannot be explained by the theory, then you've got to change something about the theory. The theoretical constraints of a precise theory are necessary in order to do science rather than fiction. 
GB: Do think that makes you more careful in the way that you use language when you write about theories in science?

AS: Yes. Metaphors are the way we talk, and if they help you to flesh out the concepts, it's fine. You can live everyday life saying that in winter, the trees are naked, but [there's a problem] the moment you take it seriously. Trees cannot be naked-they don't wear clothing. When you're using a metaphor to express a scientific concept and all of a sudden you start to believe in it, that is a problem and philosophers have studied that.

GB: But it is interesting, too, thinking about both the limits of language and using language as a communication tool and-like you're saying-metaphor as a way to communicate but also [a limitation].

AS: But it's also the way you think to yourself. If you are thinking and you're going to talk to a colleague, that metaphor is already inside you because you cannot think more abstractly than that. That is the problem. Unless you are talking about doing mathematics and working with symbols, but even in that case, concepts cannot totally be reduced to symbols.

Another thing that helped me a lot is that I speak several languages. You learn that you are constrained differently by the structure of each of the languages you use. I'm not exactly the same person when I'm speaking English as when I'm speaking French or Spanish, to the point-the absurd point-where, although I write much better in English than in French, I feel more at ease in French because it allows me to be more playful than when I am speaking in English.

GB: You're thinking about the way that scientists understand their own practice and critically reflecting on why and how they're engaging with scientific discourse. In the vein of talking about language and communication, I have two last questions: do you think about the way that the science that you're doing affects so many different communities? Do you think about communicating broadly with those communities-how language plays into activism and community engagement in that way?

AS: Sure. See, for science for its own sake, normally, you talk mostly among scientists. But when you touch on disrupting the endocrine system, for example, something that would impinge on public health and environment, you have to communicate with laypeople. It's very difficult to do that, but yes, after so many years of doing it, I feel good talking to lay audiences. 
A scientist who doesn't talk to anybody doesn't exist. Newton said that he got where he was because he was standing on the shoulders of giants. That is a metaphor again, but it is a nice one because you don't build on science as an individual. And everything that humans do-and not only humans, every biological [entity], every bacterium doesn't exist on its own-and everything that is alive is in some sort of relationship [with] other things that are alive. I think that you have to communicate with other scientists, and you have to communicate with laypeople. I always say that if I'm paid by taxpayers to do something, I must communicate the results of my research to them. They have the right to know; I have the obligation to transfer this knowledge, particularly if it has consequences that affect their health and that of their families. Some people may not want to know. They can choose; they are free, but I think I have the duty to communicate the results obtained with their economic support.

\section{Author Bio}

Gracen Brilmyer is a PhD Candidate in the Department of Information Studies at UCLA, whose research lies at the intersection of disability studies, archival studies and the history of science. For more: gracenbrilmyer.com 